\title{
Waiting Time for Start of Outpatient Cardiac Rehabilitation: Correlations of Non Compliance to Systematic Referral After Coronary Artery Bypass Surgery
}

\author{
Ali Soroush, ${ }^{1,2}$ Behzad Heydarpour, ${ }^{1}$ Mozhgan Saeidi,, ${ }^{1,}$ Parvin Ezzati, ${ }^{1}$ and Saeid Komasi ${ }^{1,3}$ \\ ${ }^{1}$ Cardiac Rehabilitation Center, Imam Ali Hospital, Kermanshah University of Medical Sciences, Kermanshah, Iran \\ ${ }^{2}$ Lifestyle Modification Research Center, Imam Reza Hospital, Kermanshah University of Medical Sciences, Kermanshah, Iran \\ ${ }^{3}$ Clinical Research Development Center, Imam Reza Hospital, Kermanshah University of Medical Sciences, Kermanshah, Iran \\ "Corresponding author: Mozhgan Saeidi, Cardiac Rehabilitation Center, Imam Ali Hospital, Kermanshah University of Medical Sciences, Shahid Beheshti Blv, Kermanshah, \\ Iran. Tel: +98-8338380698, Fax: +98-8338360043, E-mail: M_saeidi20@yahoo.com
}

Received 2016 October 30; Revised 2017 January 30; Accepted 2017 March 26.

\begin{abstract}
Objectives: To assess the waiting time, number of delays, and correlations of non-commitment to the systematic referral to the outpatient cardiac rehabilitation (CR) among coronary artery bypass surgery (CABG) patients.

Methods: The cross-sectional study data were gathered through evaluations related to 1,187 CABG patients who were referred to the outpatient CR of 1 hospital in western Iran during 2010 to 2014. The instruments included were demographics and actual risk factors checklist, single item of perceived risk factors, and Beck depression inventory (BDI). Data was analyzed via chi-square test, ANOVA, Bonferroni post hoc test, and binary logistic regression analysis.

Results: Among 1187 patients (830 male), 27\% had delayed referral, and the number of delays decreased from 2010 (49.3\%) to 2014 (7.6\%) $(\mathrm{P}<0.001)$. The mean of the waiting time to receive outpatient $\mathrm{CR}$ in western Iran was an estimated 59 days. This mean has been reduced from 66 days (2010) to 53 days (2014) $(\mathrm{P}<0.001)$. After adjustment for all demographics, the results indicated that diabetic patients $(P=0.002)$ and patients with biological $(P=0.002)$, behavioral $(P=0.003)$, or psychological $(P=0.002)$ perceived risk factors have less commitment. In addition, a family history of cardiac increases the possibility of commitment as 2.41 times ( $\mathrm{P}$ $<0.001)$.

Conclusions: Despite the progressive process of patients' admittance and acceptability of the present waiting time, especially after 2014 , it seems that more attention to diabetic patients and patients without a family history of cardiac, and modification of attitudes about multiple risk factors can associate the self-care with more responsibility and it may also be affective in the control of harm consequences through commitment to the systematic referral.
\end{abstract}

Keywords: Cardiovascular Diseases, Coronary Artery Bypass Graft, Risk Factors, Waiting Time, Systematic Referral, Rehabilitation

\section{Background}

Cardiovascular diseases (CVDs) are concerned as the main factor of mortality around the world and it is predicted that since 2030 one quadrant of the US population suffers from these diseases (1). The condition of Asian countries, especially Iran, are concerned and about 15 million among the Iranian community suffer from CVDs and millions of them are at risk (2). CVDs are concerned as a disabling condition and responsible for the death of 167 individuals /100,000 Iranian people (3). However, despite developments in treatment of CVDs and intensive cardiac care in recent decades, developments in the cardiac rehabilitation (CR) program are not considerable (4). CR includes activities such as comprehensive medical evaluation, risk factors modification, education, observation, and changing client's behavior (4) is one of the most important efforts that it recommended after a cardiac event or surgery for reduction in patients' complications (5). CR is a learning process that trains people how to live with their chronic diseases or disabled conditions and it aims to return the patient to the highest possible level of physical, psychological, social, and occupational abilities (6). In addition, participation in the CR program can reduce $25 \%$ $46 \%$ of the 10 -year mortality rate $(7,8)$.

Despite many recommendations regarding the participation in the CR program (8-11), the conducted studies in Iran demonstrated that only $15 \%$ of patients were refered for participation in this program (12). On the other hand, only $31.1 \%-49 \%$ of patients continue and finish the treatment process $(4,13)$. Among the items which endanger the advantages and the effect of CR on health are the long waiting times for the entrance to this program or patients' non-compliance to systematic referral system and delayed visit for participation (14). American pulmonary and cardiac rehabilitation association as well as European associ- 
ation of prevention and rehabilitation of cardiovascular diseases recommend the early and without delay of CR for all hospitalized patients (15). The increased waiting time and delayed access to CR not only have adverse effects on patients' body compositions (16) but also reduces the patients' commitment to treatment (14)and for each day that the waiting time increases, the probability of registration reduces $1 \%$ (17). Although the acceptable waiting time for the entrance to CR was estimated as 7 to 60 days after the cardiac event (18), the results of different studies reported it in a range of 51.8 to 101.1 days $(14,16-21)$. Based on the Grace et al. report, (18) the general mean waiting time to receive the CR is 60 days (50.7 days without delayed), however, the mean time for 14.1 patients who began CR with delay estimated as 117.8 days.

Various factors can influence the delay referred to CR. The past studies $(14,18,19)$ referred to factors such as female gender, older age, employment, lower social support, more distance to the CR center, abdominal obesity, lack of access to patient by CR team because of holidays or job problems, patient's motor disability, limited capacity of program, waiting for the result of laboratory tests or physician's response, body mass index, and body fat percentage. Conversely, the results of another study suggest that there are no significant differences between the components, which were measured routinely among patients with and without delayed referral (21).

\section{Objectives}

In the present study, we identified patients who were referred to the outpatient CR center with 1 week or more delay. In other words, these patients did not refer according to the schedule of the outpatient CR center. This issue led to the present study conducted to assess the waiting time, number of delays, and correlations of non-commitment to the systematic referral to the outpatient CR among coronary artery bypass surgery (CABG) patients.

\section{Methods}

\subsection{Design and Setting}

In this cross-sectional study, hospitalized cardiovascular patients asked to be referred to the center of outpatient CR of Imam Ali hospital-Kermanshah city after CABG during March 2010-March 2014. Kermanshah city is the center of Kermanshah province in western part of Iran that stands in 326 miles to Tehran (Capital of Iran). Based on the census of 2011, the population of this city estimated 851405 people. Imam Ali hospital of Kermanshah as a governmental hospital has 214 beds (22).

\subsection{Inclusion and Exclusion Criteria}

The inclusion criteria included the ability of appropriate communication, tendency to participation in outpatient CR and the present study, age between 30 - 80 years, absence of taking psychiatric drugs, and lack of physical and motion limitations for exercise. In addition, the patients who did not receive the surgeon's recommendation for starting outpatient CR and those who presented their delayed referrals because of medical problems or medical prohibition were excluded.

\subsection{Ethical Considerations}

Team members of the outpatient CR identified the the volunteer patients with criteria after approval of ethical committee of Kermanshah University of Medical Sciences (KUMS), which then resulted in their participation with their consent. According to the patients' insurance regarding cover of identification, the patients' medical histories, clinical conditions, demographic information, perceived risk factors, and depression were gathered by appropriate instruments.

\subsection{Participants}

Among 1,233 CABG patients, 1,198 patients who were registered in the outpatient CR program during a 5-year period (March 2010 to March 2014) and were accepted by the inclusion criteria participated in this research. In the regression analysis, 15 cases were added to the sample size for each predictive variable. Our model includes 27 predictive variables so the minimum sample size has been considered as 405 cases. If the sample size increases to 30 cases for each variable, the model indication coefficient increases dramatically (23). In this case, 810 cases are enough. Also, according to the formula $(\mathrm{N}>50+8 \mathrm{~m})$ the minimum sample size should be 266 individuals (24). All patients participated so the sample size is adequate.

\subsection{Data Collection}

The purposes of inviting patients in the first phase are the introduction to the outpatient CR program, patients' awareness, and adequate motivation for continue of treatment in outpatient phase. The team members of the outpatient CR explain the advantages and process of the outpatient CR program for patients during 1 early session and they provide a time-schedule for the beginning of course for each patient. Then the cardiologist, psychologist, nutritionist, and matron of the CR ward, separately interview the patients and record their medical history and clinical conditions in the medical records of the outpatient CR ward. Finally, the matron asked each patient during a brief interview if he/she were referred at an indicated date. At 
the end of each year, the patients' referrals to the outpatient CR center were assessed exactly. In addition, after referral to the outpatient $\mathrm{CR}$, the clinical psychologist asked and recorded the patients' demographic information and perceived risk factors during an interview with them. Beck depression inventory (BDI) is provided for patients after necessary explanations and in the case of illiteracy, the psychologist read the items and recorded the answers. Finally, demographic and medical information, actual risk factors, waiting time, and systematic referral data were collected using medical records.

\subsection{Research Instruments}

\subsubsection{Demographics and Actual Risk Factors Checklist}

Self-reported age, gender, marital status, education level, occupation, number of children, as well as insurance were collected on the baseline survey. Family history of CVDs and risk factors including current smoking, passive smoking, and hypertension/diabetes/hyperlipidemia history were classified based on the participants' reports. Body mass index (BMI) was measured and calculated carefully by a nutrition consultant. Furthermore, the illness risk factors such as hypertension, diabetes, and hyperlipidemia were matched and verified through medical records audited by the research team. All data was registered in the demographics and risk factors checklist. The data were used to calculate actual cardiovascular risk (absence of risk $=0$, presence of risk =1): high blood pressure, diabetes, high cholesterol, cigarette smoking, passive smoking, and family history of CVDs.

\subsubsection{Waiting Time}

The dates of surgery and starting to exercise were extracted from patients' medical records. The waiting time was estimated from the date of CABG to date of exercise as day.

\subsubsection{Systematic Referral}

The researchers provided the exact referral time and the written time schedule for patients before discharge of hospital. Therefore, the patients were divided into 2 groups: patients who referred with 1 week or more delay $(=0)$ and those who referred without delay or less than 1 week $(=1)$.

\subsubsection{The Perceived Risk Factors}

There are various methods and instruments such as the revised illness perception questionnaire (25-27) for measurement of the perceived risk factors. However, according to the Komasi and Saeidi category about the perceived risk factors for CVDs (2), we applied a single item that the "Which cause you know as the main factor for your disease?" $(28,29)$. Based on the mentioned category, the answers were divided into 5 categories which included biological (gender, age, family history), environmental (smoke and toxic substances, polluted weather, passive smoking), physiological (hypertension, diabetes, hyperlipidemia, tension of physical activity), and psychological (stress, anxiety, grief and depression, anger and hostility, spouse's mal-behavior) risk factors (30). In addition, the patients without a perceived risk factor were identified.

\subsubsection{The Beck Depression Inventory (BDI)}

Beck and colleagues designed a 21-item questionnaire to assess depression. Each item receives a score of $0-3$, therefore, the total score varies from 0 to 63. A score of 0 4 indicates possible denial, 5 - 9 indicates very mild depression, 10 - 18 indicates mild to moderate depression, 19 - 29 indicates moderate to severe depression, and a score over 30 indicates severe depression. Beck et al. (31) reported the consistency when patients were retested within 1 week as 0.93. Based on studies done in Iran, validity of the questionnaire was approved and the reliability of the inventory was reported between $0.70-0.90$ (32).

\subsection{Data Analysis}

The mean waiting time during the 5-year period was assessed and compared via ANOVA test. The multiple comparison of the mean waiting time between every year to others was done by post hoc Bonferroni test. The chisquare test was used to compare the yearly prevalence of patients who had entered to CR with delay. Moreover, the patients' characteristics with and without delayed systematic referrals were assessed through chi-square tests for nominal and categorized variables and ANOVA test for continuous variables. The percentages related to noncontinuous variables and the mean and standard deviations related to continuous variables were reported. Finally, binary logistic regression analysis was used for identification of the related correlations with delayed systematic referrals. All of the variables such as gender, age, marital status, education level, occupation, number of children, health insurance, perceived risk factors, and actual risk factors include history of diabetes, hypertension, hyperlipidemia, BMI, family history of cardiac, active or passive smoking, and depression were analyzed. The analysis was performed via SPSS 20 software and the significant level was concerned as $\mathrm{P}<0.05$.

Before analysis, the statistical assumptions of binary logistic regression analysis were assessed. First, normality and outliers were measured with 2 standard deviations and according to that the maximum value (Mahalanobis 
distance $=48.034)$ of dependent variables was higher than critical value (40.113), it was indicated that there was a tilt in data. After exclusion of 11 participants based on Mahalanobis distance, the mean and trimmed mean 5\% were closed together (15.98 and 15.42) so the absence of outlier was approved and the other variables were analyzed. In addition, the collinearity evaluation was performed. The tolerance of each variable was more than 0.1 and VIF was less than 10 for each dependent variable, therefore it was indicated that there was no multicollinearity. The main analysis was performed after observing and lack of out-rage from pre-assumptions (24).

\section{Results}

\subsection{Changing Waiting Time for outpatient CR}

Among the total participants (1187 patients; 830 men and 357 women) in the outpatient CR program, 231 patients (27\%) had delayed referral and 866 patients (73\%) referred on time. Table 1 presents that despite delays of some patients during 2010 to 2014, the waiting time decreased to 59 days from 106 days (mean: 80 days) and this change in the delivery of outpatient $\mathrm{CR}$ services is significant ( $\mathrm{P}$ $<0.001$ ). Furthermore, Table 1 presents the waiting time among commitment and non-commitment patients to the systematic referral. After patients with delayed referral were excluded, it was indicated that the mean waiting time reduced to 53 days from 66 days (mean: 59 days). It means that the delivery rate of outpatient CR services improved significantly $(\mathrm{P}<0.001)$ but the mean delay time among non-commitment patients does not present considerable change $(\mathrm{P}=0.598)$. The results of Bonferroni post hoc test in Table 2 shows that among the total patients, the difference between 2010 and 2011 with the recent 3 years are significant. It means that the mean of the waiting time has reduced significantly since $2012(\mathrm{P}<0.001)$. In addition, among the patients who referred at time, the mean of the waiting time has reduced significantly since 2012 and there is a significant difference between 2014 with the prior years $(\mathrm{P}<0.05)$. It means that the reduction process of the mean of the waiting time be continued (Figure 1).

\subsection{Changes in the Number of Patients Who Refer to Outpatient CR with Delay}

The results of the chi-square test showed that $65.7 \%$ patients who had delayed referral to the outpatient CR related to 2010 -2011, otherwise $34.3 \%$ of them related to 2012 2014. Therefore, it is indicated that the delayed referral was significantly reduced during the past 3 years $\left(\chi^{2}=147.033\right.$, $\mathrm{P}<0.001)$. In addition, the results of the Pearson correlation test indicated that there is a significant relationship between the increase of waiting time and number of delays $(\mathrm{r}=956 ; \mathrm{P}=0.011)$ as well as the increase of waiting time leads to increase of delays.

\subsection{Correlates of non-compliance to systematic referral}

The patients characteristics are presented in Table 3. As seen, there are differences between groups in number of children, family history of cardiac, and diabetes at baseline. It means that patients with more children have more delayed referrals to outpatient $C R(P=0.014)$. Diabetic patients are less committed to the systematic referral ( $P$ $<0.001$ ) and patients with family history of cardiac are more committed to the systematic referral compared to others $(\mathrm{P}<0.001)$. Table 4 displays the adjusted odds ratio, $95 \%$ confidence interval, and p value for each covariate included in the binary logistic regression model. Overall, 5 variables were found to be independently significantly associated with delayed referral. Indicators of effect size (Cox and Snell $\mathrm{R}^{2}=0.059$; Nagelkerke $\mathrm{R}^{2}=0.086$ ) suggested that our model can explain $5.9 \%$ to $8.6 \%$ of variance of delayed referral. Table 4 shows that after adjustment for all demographics, diabetic patients $(\mathrm{P}=0.002)$ and those with biological ( $\mathrm{P}<0.002)$, behavioral $(\mathrm{P}<0.003)$, or psychological $(\mathrm{P}<0.002)$ perceived risk factors are less commitment to the systematic referral. In fact, the history of diabetes, presence of one biological, behavioral, or psychological perceived risk factor can reduce the probability of at time referral to the outpatient CR 0.64, 0.23, 0.46, and 0.27 times respectively. In addition, patients with a family history of cardiac are more committed to the systematic referral compared to others $(\mathrm{P}<0.001)$ and the component can increase the probability at the time referral 2.41 times.

\section{Discussion}

Although the advantage of outpatient CR in patients' improvement is approved, the reduction in waiting time after cardiac event can increase the probability of registration, commitment, body composition, and improvement of clinical parameters (14-17). Our study aimed 3 purposes: The first goal was the assessment of changes in the waiting time during the past 5 years. According to the prior studies that they reported this mean time (waiting time after CABG) between 51.8 to 101.1 days $(14,16-21)$, the present results indicated that the mean waiting time is 80 days and has been reduced from 106 days to 59 days during 2010 2014. In addition, after exclusion of non-commitment patients to the systematic referral, the results showed that the mean of the waiting time has been reduced from 66 days to 53 days (the total mean: 59 days). It means that the 


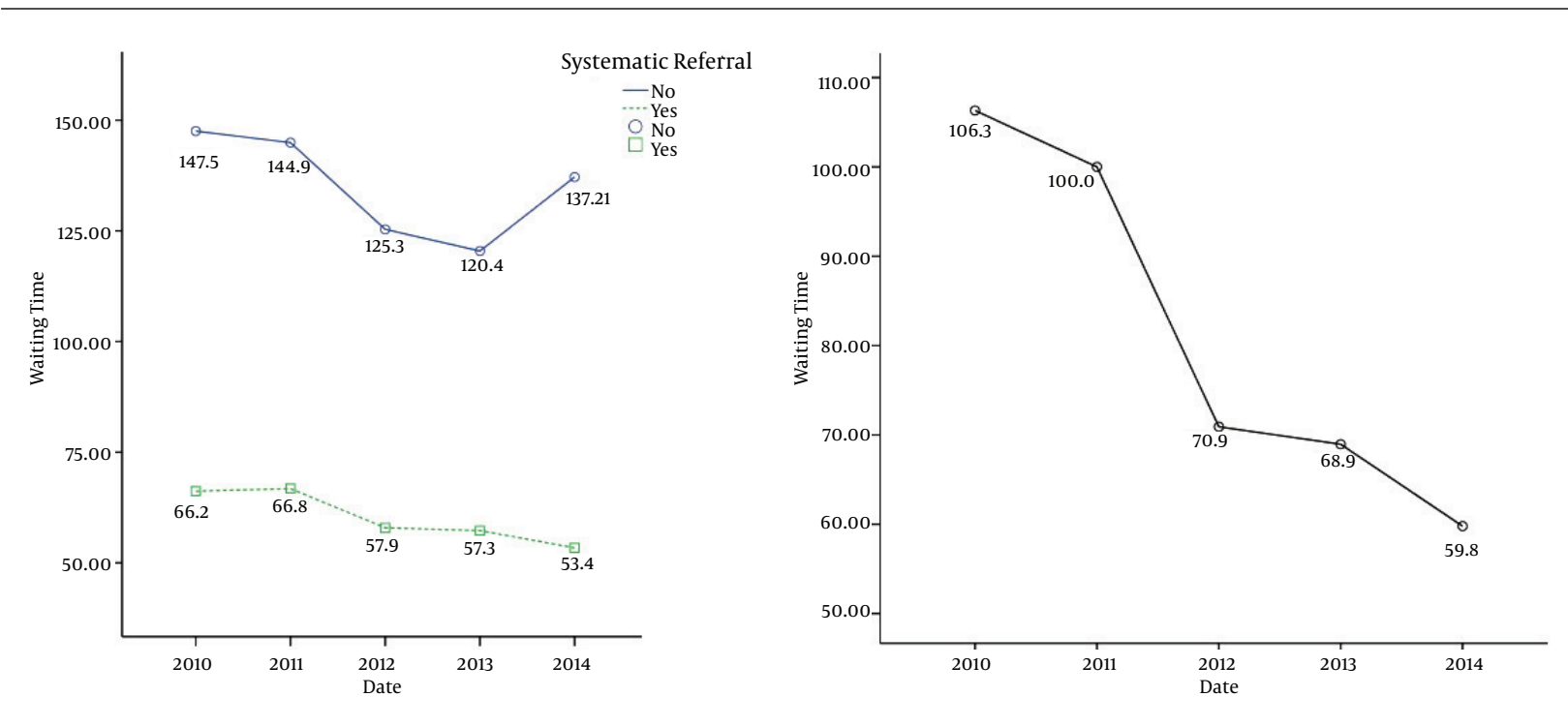

Figure 1. Changes of Systematic Referral During Years 2010 - 2014

Table 1. Comparison of Waiting Time Between Patients with and Without Delayed Referral

\begin{tabular}{|c|c|c|c|c|c|}
\hline Year & Systematic Referral & No. (\%) & Mean \pm SD & $\mathbf{F}$ & PValue $^{a}$ \\
\hline \multirow{3}{*}{2010} & On time referral & $112(50.7)$ & $66.2 \pm 18.9$ & \multirow{17}{*}{$26.431,0.692,20.694$} & \multirow{17}{*}{$0.0005,0.598,0.0005$} \\
\hline & Delayed referral & $109(49.3)$ & $147.5 \pm 73.9$ & & \\
\hline & Total & $221(100)$ & $106.3 \pm 67.3$ & & \\
\hline \multirow{2}{*}{2011} & On time referral & $138(57.5)$ & $66.8 \pm 15.1$ & & \\
\hline & Total & $240(100)$ & $100 \pm 130$ & & \\
\hline \multirow{3}{*}{2012} & On time referral & $134(80.7)$ & $57.9 \pm 13.4$ & & \\
\hline & Delayed referral & $32(19.3)$ & $125.3 \pm 29.3$ & & \\
\hline & Total & $166(100)$ & $70.9 \pm 31.9$ & & \\
\hline \multirow{3}{*}{2013} & On time referral & $264(81.5)$ & $57.3 \pm 14.9$ & & \\
\hline & Delayed referral & $60(18.5)$ & $120.4 \pm 32.1$ & & \\
\hline & Total & $324(100)$ & $68.9 \pm 31.2$ & & \\
\hline \multirow{3}{*}{2014} & On time referral & $218(92.4)$ & $53.4 \pm 10.7$ & & \\
\hline & Delayed referral & $18(7.6)$ & $137.2 \pm 46.1$ & & \\
\hline & Total & $236(100)$ & $59.8 \pm 27.5$ & & \\
\hline \multirow{3}{*}{ Total } & On time referral & $866(73.0)$ & $59.1 \pm 15.2$ & & \\
\hline & Delayed referral & $321(27.0)$ & $138.8 \pm 117.3$ & & \\
\hline & Total & $1187(100)$ & $80.6 \pm 71.6$ & & \\
\hline
\end{tabular}

${ }^{\mathrm{a}}$ ANOVA performed for the analysis. The means difference is significant at the 0.01 level.

rate of outpatient CR services has been improved significantly. Therefore, according to the acceptable mean, waiting time is reported as 7 - 60 days after cardiac event (18), the mean time of 59 days is acceptable for beginning of outpatient CR. Perhaps, the main reason for this condition is related to the basic changes in structure of patients' admission and registration. The outpatient $\mathrm{CR}$ program was conducted as a closed group format in 2011 and before. In 
Table 2. Differences Between Years 2010 - 2014 in Term of Systematic Referral

\begin{tabular}{|c|c|c|c|c|c|}
\hline \multirow[t]{2}{*}{ Date } & & \multirow[t]{2}{*}{ Mean Difference ${ }^{a}$} & \multicolumn{2}{|c|}{$\mathbf{9 5 \%}$ Confidence Interval } & \multirow[t]{2}{*}{ PValue } \\
\hline & & & Lower bound & Upper bound & \\
\hline \multicolumn{6}{|c|}{$2010^{b}$} \\
\hline & 2011 & 6.312 & -11.877 & 24.502 & 0.999 \\
\hline & 2012 & 35.401 & 15.361 & 55.441 & 0.0005 \\
\hline & 2013 & 37.362 & 20.351 & 54.374 & 0.0005 \\
\hline & 2014 & 46.532 & 28.268 & 64.796 & 0.0005 \\
\hline \multicolumn{6}{|c|}{$2011^{b}$} \\
\hline & 2012 & 29.088 & 9.391 & 48.785 & 0.0005 \\
\hline & 2013 & 31.050 & 14.444 & 47.656 & 0.0005 \\
\hline & 2014 & 40.220 & 22.333 & 58.107 & 0.0005 \\
\hline \multicolumn{6}{|c|}{$2012^{b}$} \\
\hline & 2013 & 1.961 & -16.652 & 20.575 & 0.999 \\
\hline & 2014 & 11.131 & -8.633 & 30.896 & 0.999 \\
\hline \multicolumn{6}{|c|}{$2013^{b}$} \\
\hline & 2014 & 9.169 & -7.516 & 25.856 & 0.999 \\
\hline \multicolumn{6}{|c|}{$2010^{c}$} \\
\hline & 2011 & -0.593 & -5.750 & 4.563 & 0.999 \\
\hline & 2012 & 8.278 & 3.087 & 13.469 & 0.0005 \\
\hline & 2013 & 8.902 & 4.332 & 13.472 & 0.0005 \\
\hline & 2014 & 12.801 & 8.087 & 17.516 & 0.0005 \\
\hline \multicolumn{6}{|c|}{$2011^{c}$} \\
\hline & 2012 & 8.871 & 3.954 & 13.789 & 0.0005 \\
\hline & 2013 & 9.495 & 5.238 & 13.752 & 0.0005 \\
\hline & 2014 & 13.395 & 8.984 & 17.806 & 0.0005 \\
\hline \multicolumn{6}{|c|}{$2012^{C}$} \\
\hline & 2013 & 0.623 & -3.674 & 4.921 & 0.9999 \\
\hline & 2014 & 4.523 & 0.072 & 8.974 & 0.043 \\
\hline \multicolumn{6}{|c|}{$2013^{c}$} \\
\hline & 2014 & 3.899 & 0.192 & 7.607 & 0.032 \\
\hline
\end{tabular}

this format, all patients were asked to participate in 24 integrated sessions (for 8 weeks) of exercise, nutrition, and psychological training. Male and female patients participated 3 days of the week separately. Therefore, the practitioners were not able to admit new patients during the 60 days of the program and this issue led to an increase in the waiting time. This program has been changed to an open format since 2012 so every patient can enter this outpatient CR program and begin scheduled exercise with minimum delay.

The second purpose was the assessment of the number of patients who entered to the outpatient CR program with delay during 2010 - 2014. The results presented that $27 \%$ of patients referred with delay and that this percentage is 2 times higher than the percentage that has been reported (14.1\%) by Grace et al. (18), however, $65.7 \%$ of the delays were related to 2010 and 2011 and the mean of delays for each year during 2010 - 2014 were $49.3 \%, 42.5 \%, 19.3 \%, 18.5 \%$, and
$7.6 \%$, respectively. Thus, the prevalence rate of delays in 2014 was half of the percentage of the Grace et al. study. (18) It means that the number of patients with delays has been reduced significantly and almost all patients were committed to the systematic referral. It is probable that one of the reasons of a reduction in delays is the reduced mean waiting time. The results of one study (17) indicates that the probability of registration in CR may reduce $1 \%$ if the waiting time increase one day. In the present study, the relation between the waiting time and delays was approved so it be suggested that the dramatic reduction of the mean waiting time during the past 3 years led to reduction of delays. Another explanation is the patients' invitation before hospital discharge for participation in outpatient CR session. The advantages of outpatient CR were explained exactly and the primary evaluation was conducted after introduction of different parts of program. In this session, the start date, number of sessions, time duration of each session, and the estimated costs according the type of health insurance and the importance of corporation and regular commitment to the program were explained exactly. It may lead the patients to make a decision for participation in the program with more knowledge (4). This session probably may enhance the patients' motivations and their knowledge participation in the outpatient CR program.

The third purpose was the assessment of the effective factors in the patients non-commitment to the systematic referral and delayed refers. Our results showed that considering the adjustment for all demographic variables such as age, gender, education level, and occupation, all diabetic patients and those with biological, behavioral, or psychological perceived risk factors are less committed to the systematic referral compared to the patients without a perceived risk factor and they possibly enter to the outpatient $\mathrm{CR}$ with delay. It seems that diabetic patients, through association between their cardiac disease with this risk factor (1) and its control perception by medicines, nutrition regimen, and adequate activity after CABG do not worry about probable outcomes of this risk factor (5). These individuals feel they have a good control on the main factor of their cardiac disease and it may lead to the reduction of their worry and anxiety (5). The lack of worry about negative outcomes may challenge the commitment to the systematic referral and at-time refers.

On the other hand, according the health belief model (33), patients' cognitive beliefs and their emotional reactions to disease and treatment (34) can independently predict their health behavior. The patients with perceived risk factors are younger than patients without a perceived risk factor (2) and they believe to weak probability of the future outcomes for themselves. In opposite, they have more perceived control on their disease and it is more possible that 
Table 3. Baseline Demographic and Clinical Characteristics in the Overall Population and in those with and Without Delayed Systematic Referral ${ }^{\mathrm{a}, \mathrm{b}}$

\begin{tabular}{|c|c|c|c|c|}
\hline Characteristic & Overall Population, $\mathrm{N}=1187$ & Delayed Systematic Referral, N= 321 (27\%) & On Time Systematic Referral, N= 866 (73\%) & PValue $^{c}$ \\
\hline Sex & & & & 0.75 \\
\hline Male & 69.9 & 69.1 & 70.2 & \\
\hline Female & 30.1 & 30.9 & 29.8 & \\
\hline Age & $58.3 \pm 8.8$ & $58.9 \pm 8.7$ & $58.0 \pm 8.8$ & 0.11 \\
\hline Education degree & & & & 0.488 \\
\hline Illiterate & 38.4 & 41.4 & 37.3 & \\
\hline Under high school & 31.6 & 31.8 & 31.5 & \\
\hline Less than diploma & 13.5 & 13.1 & 13.6 & \\
\hline Diploma & 13.6 & 11.8 & 14.3 & \\
\hline Under bachelor & 1.4 & 1.6 & 1.4 & \\
\hline Bachelor & 1.3 & 0.3 & 1.7 & \\
\hline Master & 0.1 & 0.0 & 0.1 & \\
\hline $\mathrm{PhD}$ & 0.1 & 0.0 & 0.1 & \\
\hline Marital status & & & & 0.403 \\
\hline Married & 90.0 & 88.8 & 90.5 & \\
\hline Single, divorced and separated & 10.0 & 11.2 & 9.5 & \\
\hline Occupation & & & & 0.726 \\
\hline Market & 35.9 & 34.9 & 36.2 & \\
\hline Housewife & 27.7 & 28.0 & 27.6 & \\
\hline Retired & 25.9 & 27.8 & 25.2 & \\
\hline Clerk & 10.5 & 9.3 & 11.0 & \\
\hline Number of child & $4.6 \pm 2.3$ & $4.8 \pm 2.3$ & $4.5 \pm 2.2$ & $0.014^{*}$ \\
\hline Insurance & 96.3 & 95.9 & 96.3 & 0.774 \\
\hline \multicolumn{5}{|l|}{ Risk factors history } \\
\hline Diabetes & 37.6 & 45.5 & 34.6 & $0.001^{*}$ \\
\hline Hypertension & 33.2 & 32.4 & 33.5 & 0.733 \\
\hline Hyperlipidemia & 30.8 & 31.5 & 30.6 & 0.766 \\
\hline Family history & 19.1 & 10.9 & 22.2 & $0.0005^{*}$ \\
\hline Smoking & 39.4 & 41.4 & 38.7 & 0.381 \\
\hline Passive smoking & 9.9 & 10.3 & 9.8 & 0.807 \\
\hline Depression & $16.78 \pm 3.54$ & $17.06 \pm 3.47$ & $16.67 \pm 3.57$ & 0.090 \\
\hline BMI & $26.50 \pm 3.64$ & $26.51 \pm 3.59$ & $26.50 \pm 3.66$ & 0.978 \\
\hline Perceived risk factors & & & & 0.094 \\
\hline Unawareness & 12.3 & 7.8 & 14.0 & \\
\hline Biological beliefs & 3.3 & 3.2 & 3.3 & \\
\hline Environmental beliefs & 4.2 & 3.7 & 4.4 & \\
\hline Physiological beliefs & 10.5 & 10.3 & 10.6 & \\
\hline Behavioral beliefs & 30.9 & 33.6 & 29.9 & \\
\hline Psychological beliefs & 38.8 & 41.4 & 37.8 & \\
\hline
\end{tabular}

${ }^{\mathrm{a}}$ Values are expressed as number percent.

${ }^{b}$ Significant difference between patients with and without delayed systematic referral for each characteristic ${ }^{*} \mathrm{P}<0.05$

${ }^{\mathrm{c}}$ Chi-square test performed for nominal and categorical variables. ANOVA performed for continuous variables.

they have less commitment and discontinue outpatient CR (25). In addition, the awareness of etiology and presence of a perceived risk factor may lead to patients feeling about the control of disease through change of life style. This issue causes less attention to outpatient CR and it may increase the occurrence of delay.

Finally, it was indicated that patients with a family history of cardiac have more commitment to the systematic referral compared to others and this risk factor increases the possibility of at-time refers 2.41 times. The uncontrollable hereditary and biological nature of the disease may lead patients to know themselves to be more at-risk (35) and they have higher perceived risk (36).

\subsection{Strengths, Limitations and Recommendations}

One of the positive points of our study is the suitable sample size compared to the number of assessed compo- 
Table 4. Predictors of Delayed Systematic Referral in the Overall Population ${ }^{\mathrm{a}, \mathrm{b}}$

\begin{tabular}{|c|c|c|c|}
\hline Characteristic & Delayed Systematic Referral (\%) & Adjusted Odd Ratio (AOR) & P Value \\
\hline \multicolumn{4}{|l|}{ Sex } \\
\hline Male & 26.7 & Referent & \\
\hline Female & 27.6 & $1.91(0.21-17.23)$ & 0.565 \\
\hline Age & . & $1.00(0.98-1.02)$ & 0.824 \\
\hline \multicolumn{4}{|l|}{ Education degree } \\
\hline Illiterate & 29.2 & Referent & \\
\hline Under high school & 27.2 & $1.24(0.81-1.92)$ & 0.326 \\
\hline Less than diploma & 26.2 & $1.26(0.70-2.28)$ & 0.441 \\
\hline Diploma & 23.5 & $1.47(0.78-2.75)$ & 0.231 \\
\hline Under bachelor & 29.4 & $1.25(0.35-4.48)$ & 0.732 \\
\hline Bachelor & 6.3 & $6.38(0.76-53.61)$ & 0.088 \\
\hline Master & 0.0 & $6.277 \mathrm{E} 8(0.000)$ & 0.999 \\
\hline $\mathrm{PhD}$ & 0.0 & 7.019E8 $(0.000)$ & 0.999 \\
\hline \multicolumn{4}{|l|}{ Marital status } \\
\hline Married & 26.7 & Referent & \\
\hline Single, divorced and separated & 30.2 & $0.92(0.56-1.51)$ & 0.733 \\
\hline \multicolumn{4}{|l|}{ Occupation } \\
\hline Market & 26.3 & Referent & \\
\hline Housewife & 27.4 & $0.60(0.07-5.38)$ & 0.648 \\
\hline Retired & 29.0 & $0.76(0.50-1.14)$ & 0.184 \\
\hline Clerk & 24.0 & $0.82(0.48-1.43)$ & 0.495 \\
\hline Number of child & - & $0.93(0.87-1.00)$ & 0.059 \\
\hline Insurance & 26.9 & $1.03(0.52-2.05)$ & 0.936 \\
\hline \multicolumn{4}{|l|}{ Risk factors history } \\
\hline Diabetes & 32.7 & $0.64(0.48-0.84)$ & $0.002^{*}$ \\
\hline Hypertension & 26.4 & $1.00(0.74-1.34)$ & 0.992 \\
\hline Hyperlipidemia & 27.6 & $1.04(0.78-1.40)$ & 0.780 \\
\hline Family history & 15.4 & $2.41(1.58-3.68)$ & $0.0005^{*}$ \\
\hline Smoking & 28.4 & $0.90(0.66-1.22)$ & 0.483 \\
\hline Passive smoking & 28.0 & $1.11(0.66-1.85)$ & 0.697 \\
\hline Depression & - & $0.97(0.93-1.01)$ & 0.165 \\
\hline BMI & - & $1.00(0.96-1.04)$ & 0.900 \\
\hline \multicolumn{4}{|l|}{ Perceived risk factors } \\
\hline Unawareness & 17.1 & Referent & \\
\hline Biological beliefs & 25.6 & $0.23(0.09-0.58)$ & $0.002^{8}$ \\
\hline Environmental beliefs & 24.0 & $0.60(0.27-1.34)$ & 0.215 \\
\hline Physiological beliefs & 26.4 & $0.55(0.30-1.03)$ & 0.060 \\
\hline Behavioral beliefs & 29.4 & $0.46(0.27-0.76)$ & $0.003^{*}$ \\
\hline Psychological beliefs & 28.8 & $0.45(0.27-0.75)$ & $0.002^{*}$ \\
\hline
\end{tabular}

nents. Other strengths are assessment of function of outpatient $\mathrm{CR}$ ward in reduction of the waiting time after CABG to start of the exercise and affective factors in the patients delays for reduction of number of delays and the waiting time. In opposite, we studied only CABG patients from 1 hospital in the western part of Iran. The lack of availability to psychiatric histories and patients psychological conditions before surgery led to exclusion of these vari- ables. It is recommended that future studies conducted with randomized cases of different parts of Iran and the patients' psychological histories be concerned for enhancement of accuracy. In addition, in the first phase of the study, asking the patients, by different matrons, during 5 years, may effect the patients' motivation for a follow-p. In future studies, it seems that a conducted interview by a special matron eliminates the potential bias in the results. Fi- 
nally, our model explained only $5.9 \%$ to $8.6 \%$ of variance of delayed refers. Therefore, the other social and clinical parameters are needed to be assessed in future studies.

\subsection{Conclusions}

The mean waiting time to receive outpatient $\mathrm{CR}$ is 59 days in the western part of Iran and it has been reduced to 53 days from 66 days during 2010 - 2014. In addition, $27 \%$ of patients referred with delay and this mean percentage has been reduced to 7.6\% in 2014 (49.3\% in 2010). Despite the progressive process of patients' admittance and acceptability of the present waiting time especially after 2014 , it seems that more attention to diabetic patients and those without a family history of cardiac and modification of attitudes about multiple risk factors can associate the self-care with more responsibility and it may be affective in the control of harm consequences through commitment to the systematic referral.

\section{Acknowledgments}

It is hereby deemed necessary to thank and appreciate the staff of Cardiac Rehabilitation Unit of the Imam Ali hospital for their cooperation in providing data.

\section{Footnotes}

Conflict of Interests: None declared. Funding/Support: None.

\section{References}

1. Saeidi M, Komasi S, Soroush A, Zakiei A, Shakeri J. Gender differences in patients' beliefs about biological, environmental, behavioral, and psychological risk factors in a cardiac rehabilitation program. $J$ Cardio-Thorac Med. 2014;2(4):215-20. doi: 10.22038/jctm.2014.3490.

2. Komasi S, Saeidi M. Aging is an important cause for a lack of understanding of the main risk factor in cardiac rehabilitation patients. Thrita. 2015;4(4) doi: 10.5812/thrita.32751.

3. Saeidi M, Soroush A, Komasi S, Moemeni K, Heydarpour B. Attitudes toward cardiovascular disease risk factors among patients referred to a cardiac rehabilitation center: Importance of psychological attitudes. Shiraz E-Med J. 2015;16(7) doi:10.17795/semj22281.

4. Heydarpour B, Saeidi M, Ezzati P, Soroush A, Komasi S. Sociodemographic Predictors in Failure to Complete Outpatient Cardiac Rehabilitation. Ann Rehabil Med. 2015;39(6):863-71. doi: 10.5535/arm.2015.39.6.863. [PubMed: 26798599].

5. Saeidi M, Komasi S, Heydarpour B, Karim H, Nalini M, Ezzati P. Predictors of Clinical Anxiety Aggravation at the End of a Cardiac Rehabilitation Program. Res Cardiovasc Med. 2016;5(1):ee30091. doi: 10.5812/cardiovascmed.30091. [PubMed: 26937419].

6. Komasi S, Saeidi M, Montazeri N, Masoumi M, Soroush A, Ezzati P. Which Factors Unexpectedly Increase Depressive Symptom Severity in Patients at the End of a Cardiac Rehabilitation Program?. Ann Rehabil Med. 2015;39(6):872-9. doi: 10.5535/arm.2015.39.6.872. [PubMed: 26798600].
7. Jackson L, Leclerc J, Erskine Y, Linden W. Getting the most out of cardiac rehabilitation: a review of referral and adherence predictors. Heart. 2005;91(1):10-4. doi: 10.1136/hrt.2004.045559. [PubMed: 15604322].

8. Pack QR, Goel K, Lahr BD, Greason KL, Squires RW, Lopez-Jimenez F, et al. Participation in cardiac rehabilitation and survival after coronary artery bypass graft surgery: a community-based study. Circulation. 2013;128(6):590-7. doi: 10.1161/CIRCULATIONAHA.112.001365. [PubMed: 23836837].

9. Reeves GR, Whellan DJ. Recent advances in cardiac rehabilitation. Curr Opin Cardiol. 2010;25(6):589-96. doi: 10.1097/HCO.0b013e32833f0208. [PubMed: 20881485].

10. Mampuya WM. Cardiac rehabilitation past, present and future: an overview. Cardiovasc Diagn Ther. 2012;2(1):38-49. doi: 10.3978/j.issn.2223-3652.2012.01.02. [PubMed: 24282695].

11. Komasi S, Saeidi M, Ezzati P, Amirian J. How Can we deliver outpatient cardiac rehabilitation services to all low-risk patients in Iran?. Res Cardiovasc Med. 2016;6(2) doi:10.5812/cardiovascmed.43585.

12. Moradi B, Maleki M, Esmaeilzadeh M, Abkenar HB. Physician-related factors affecting cardiac rehabilitation referral. J Tehran Heart Cent. 2011;6(4):187-92. [PubMed: 23074367].

13. Moradi B, Esmaeilzadeh M, Maleki M, Sari L. Factors associated with failure to complete phase ii cardiac rehabilitation: Survey registry in rajaie cardiovascular medical and research center. Int Cardiovasc Res J. 2011;5(4):139-42. doi: 10.5812/icrj.4370.

14. Marzolini S, Blanchard C, Alter DA, Grace SL, Oh PI. Delays in Referral and Enrolment Are Associated With Mitigated Benefits of Cardiac Rehabilitation After Coronary Artery Bypass Surgery. Circ Cardiovasc Qual Outcomes. 2015;8(6):608-20. doi: 10.1161/CIRCOUTCOMES.115.001751. [PubMed: 26555125].

15. Collins ZC, Suskin N, Aggarwal S, Grace SL. Cardiac rehabilitation wait times and relation to patient outcomes. Eur J Phys Rehabil Med. 2015;51(3):301-9. [PubMed: 25213305].

16. Marzolini S, Grace SL, Brooks D, Corbett D, Mathur S, Bertelink R, et al. Time-to-referral, use, and efficacy of cardiac rehabilitation after heart transplantation. Transplantation. 2015;99(3):594-601. doi: 10.1097/TP.0000000000000361. [PubMed: 25119127].

17. Russell KL, Holloway TM, Brum M, Caruso V, Chessex C, Grace SL. Cardiac rehabilitation wait times: effect on enrollment. J Cardiopulm Rehabil Prev. 2011;31(6):373-7. doi: 10.1097/HCR.ob013e318228a32f. [PubMed: 21826016].

18. Grace SL, Gravely-Witte S, Li J, Fair T, Suskin N. Wait times and delays from cardiac rehabilitation referral receipt to intake.J Cardiopulm Rehabil Prev. 2008;28(5):338. doi:10.1097/01.HCR.0000336156.40182.2b.

19. Grace SL, Tan Y, Marcus L, Dafoe W, Simpson C, Suskin N, et al. Perceptions of cardiac rehabilitation patients, specialists and rehabilitation programs regarding cardiac rehabilitation wait times. BMC Health Serv Res. 2012;12:259. doi: 10.1186/1472-6963-12-259. [PubMed: 22897912].

20. Grace SL, Parsons TL, Heise K, Bacon SL. The Canadian Cardiac Rehabilitation Registry: Inaugural Report on the Status of Cardiac Rehabilitation in Canada. Rehabil Res Pract. 2015;2015:278979. doi: 10.1155/2015/278979. [PubMed: 26357574].

21. Dulay D, Abramowitz D, Huang S, Suskin N, Unsworth K, Humen D. The impact of wait times on outcomes measured in cardiac rehabilitation. Can J Cardiol. 2007;23.

22. Komasi S, Saeidi M. What is role of sex and age differences in marital conflict and stress of patients under Cardiac Rehabilitation Program?. ARYA Atheroscler. 2016;12(3):138-45. [PubMed: 27752271].

23. Beshlideh K. Research methods and statistical analysis of research examples using SPSS and AMOS [In Persian]. Iran: Publication of Ahvaz; 2012.

24. Pallant J. SPSS survival manual: A step by step guide to data analysis using SPSS for Windows (Version 12). 2nd ed. Australia: Allen \& Unwin; 2005. pp. 142-52. 
25. Yohannes AM, Yalfani A, Doherty P, Bundy C. Predictors of drop-out from an outpatient cardiac rehabilitation programme. Clin Rehabil. 2007;21(3):222-9. doi: 10.1177/0269215506070771. [PubMed: 17329279].

26. Grace SL, Krepostman S, Brooks D, Arthur H, Scholey P, Suskin N, et al. Illness perceptions among cardiac patients: relation to depressive symptomatology and sex.JPsychosom Res. 2005;59(3):153-60. doi: 10.1016/j.jpsychores.2005.05.005. [PubMed:16198188].

27. Petrie KJ, Weinman J. Patients' perceptions of their illness. Curr Dir Psychol Sci. 2012;21(1):60-5. doi: 10.1177/0963721411429456.

28. Saeidi M, Komasi S. Open single item of perceived risk factors (OSIPRF) toward cardiovascular diseases is an appropriate instrument for evaluating psychological symptoms. J Cardio-Thorac Med. 2016;4(4):527-8. doi: 10.22038/jctm.2016.7874.

29. Komasi S, Saeidi M. A perceived risk factor may lead to increased anxiety and depression in cardiovascular patients. Jundishapur J Chronic Dis Care. 2016;5(4) doi:10.17795/jjcdc-34159.

30. Komasi S, Saeidi M. Screening For Depressive Symptoms at the Beginning of Outpatient Cardiac Rehabilitation by Assessed Perceived Risk Factors by Patients. Clin Med Rev Case Rep. 2015;2(8).

31. Beck AT, Steer RA, Carbin MG. Psychometric properties of the Beck depression inventory: Twenty-five years of evaluation. Clinical Psychology Review. 1988;8(1):77-100. doi:10.1016/0272-7358(88)90050-5.
32. Karami J, Komasi S, Maesoomi M, Saeidi M. Comparing the effects of two methods of relaxation and interpersonal cognitive problem solving (ICPS) on decreasing anxiety and depression in cardiac rehabilitation patients [In Pesrian]. Urmia Med J. 2014;25(4):298-308.

33. van der Wal MH, Jaarsma T, Moser DK, Veeger NJ, van Gilst WH, van Veldhuisen DJ. Compliance in heart failure patients: the importance of knowledge and beliefs. Eur Heart J. 2006;27(4):434-40. doi: 10.1093/eurheartj/ehi603. [PubMed: 16230302].

34. Phillips LA, Diefenbach MA, Abrams J, Horowitz CR. Stroke and TIA survivors' cognitive beliefs and affective responses regarding treatment and future stroke risk differentially predict medication adherence and categorised stroke risk. Psychol Health. 2015;30(2):218-32. doi: 10.1080/08870446.2014.964237. [PubMed: 25220292].

35. King KM, Norris CM, Knudtson ML, Ghali WA. Risk-taking attitudes and their association with process and outcomes of cardiac care: a cohort study. BMC Cardiovasc Disord. 2009;9:36. doi: 10.1186/1471-22619-36. [PubMed: 19660137].

36. Acheson LS, Wang C, Zyzanski SJ, Lynn A, Ruffin M, Gramling R, et al Family history and perceptions about risk and prevention for chronic diseases in primary care: a report from the family healthware impact trial. Genet Med. 2010;12(4):212-8. doi:10.1097/GIM.0b013e3181d56ae6. [PubMed: 20216073]. 